TAO, Vol. 8, No. 1, 31-48, March 1997

\title{
Stress Diffusion and Spatial Migration of Aftershocks in the Hualien Area, Taiwan
}

\author{
Ting-To Yu ${ }^{1}$ and Shih-Nan Cheng ${ }^{1}$
}

(Manuscript received 16 August 1996, in final form 2 November 1996)

\begin{abstract}
Viscoelastic relaxation of asthenosphere can provide a reasonable explanation for aftershocks' expansion of the May 1986 Hualien earthquake sequence. The relaxation time of asthenosphere in the Hualien region is very short which is determined by matching the aftershock seismicity and computed results. Such short relaxation time of asthenosphere explains the relatively short reoccurrence time (20-30 years) of magnitude 7 and larger earthquakes in the Hualien region. Besides this aftershock expansion phenomena of the May 1986 earthquake, there are several major earthquakes drifting southeasterly in this region. The drifting direction of these earthquakes is opposite to the direction of plate convergence in East Taiwan. Stress redistribution after a major event plus tectonic force might be adequate to account for phenomenon of earthquake migrating in the Hualien area of Taiwan.
\end{abstract}

(Key words: Earthquake migration, Viscoelastic, Numerical model, Stress diffusion)

\section{INTRODUCTION}

A sequence of smaller earthquakes, known as aftershocks, following almost all of the large earthquakes, are related to the fault plane that slipped during the fracture. The most noted feature of an aftershock is its association with the ruptured plane of the mainshock. The temporal decay in seismicity of aftershocks can be described as Omori's law (Omori, 1894), $n=c /(k+t)^{p}$ where $n$ is the frequency of the aftershock at time $t$ after the mainshock, $k, p$ and $c$ are constants that depend on the size of the earthquake, and the $p$ value is usually close to 1.0 to 1.4. Scholz (1968) studied the microfracturing in brittle rock and concluded that aftershocks are produced by creep rupture due to stress corrosion in the regions of stress concentration following the mainshock. Another possible mechanism suggested by Nur and Booker (1972) is that aftershocks are caused by pore fluid flow. The time-dependent friction as a possible mechanism for aftershocks was proposed by Dieterich (1972) using a simple deterministic numerical fault model. Yamashita and Knopoff (1987) suggested two models to describe the behavior of aftershocks. In their Model I, aftershocks are assumed to be caused by a subsequent slip on the asperity of a fault locked during the fracture of the mainshock. In Model II, aftershocks are caused by the catastrophic coalescence of nearby small fractures with the frac-

${ }^{1}$ Institute of Earth Sciences, Academia Sinica, Nankang, Taipei, Taiwan, R.O.C. 
ture surface of the mainshock. Renschlè (1990) examined these two models on a slow crack growth process and preferred Model I. These studies focus mostly on the temporal decay pattern of aftershocks, and all the above mentioned mechanisms can explain the seismicity decaying behavior of aftershocks in time domain. However, the spatial seismicity migration of aftershocks cannot be properly explained throughout these proposed mechanisms.

There are two types of aftershocks on the fault plane that are very similar to the theoretical model of aftershocks proposed by Yamashita and Knopoff (1987). Type I represents the aftershock that occurs within the mainshock area. This is because some regions in the fault plane remained unbroken during the mainshock and the subsequent fracture may occur by the increasing load on them in combination with some time-dependent effects (Kostrov and Das, 1988, p.257). Type II represents the aftershock that occurs beyond the main fault edge due to the breaking of regions loaded by the increased concentration of stress at the fault edge with the fracture area surrounded by unslipped regions of the fault plane. Interior aftershocks, type I, are the dominant part in the observations. In most cases, the cluster of aftershocks which occurred several years after the mainshock still reveal a compact and distinct rupture zone associated with the mainshock. For example, the aftershocks of Landers, Kobe, and Northridge earthquakes, are shown in Figure 1.

The aftershock activity of the 1986 and 1991 Hualien, eastern Taiwan, earthquakes had different characteristics from those of other events. Seismicity of these two events decayed very rapidly and showed a spatial migration pattern. Those may be referred to as the 'edge aftershocks.' The interior and the edge aftershocks are mechanically different from each other and require different initial as well as boundary conditions on the fault. The goal of this study is to suggest another possible mechanism for such edge aftershocks by stress diffusion caused by the viscoelastic relaxation of asthenosphere. Results show that when the viscoelastic property is the dominant force in a short period after the mainshock, it is the source mechanism which controls both the temporal and spatial distributions of the so-called Model II or edge aftershocks.

\section{MAJOR EARTHQUAKES IN EASTERN TAIWAN FROM 1970 TO 1993}

Seismicity of Taiwan reflects the complex tectonic interaction between the Eurasian Plate

Fig. 1. (Right) (a) Aftershock seismicity and major faulting for the 1995 Kobe, Japan earthquake. Only magnitude 2 and greater from Jan. 27, 1995 to May 12, 1995 are shown. This plot is downloaded from the WWW home page of the Disaster Prevention Center, Kyoto University, Japan. (b) Aftershock seismicity of the 1992 Landers, California earthquake. This plot only shows events from July 29, 1992 to August 28, 1992. The catalog used in this plot is downloaded from the USGS southern California earthquake catalog. (c) The aftershock seismicity for the 1994 Northridge, California earthquake. This plot only shows events from Feb. 17, 1994 to Mar. 16, 1994. The catalog used in this plot is downloaded from the USGS southern California earthquake catalog. 
(a)

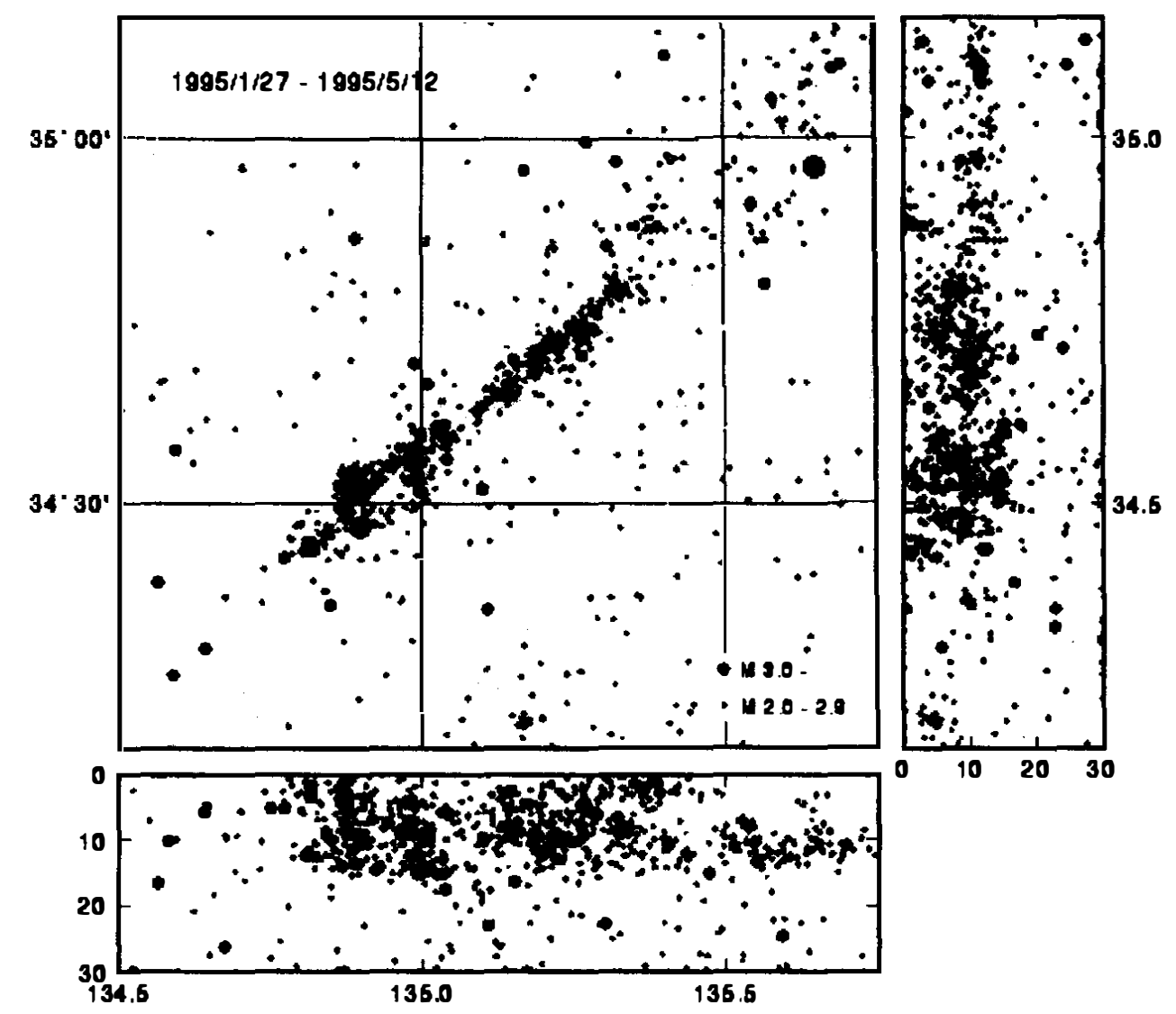

(b)

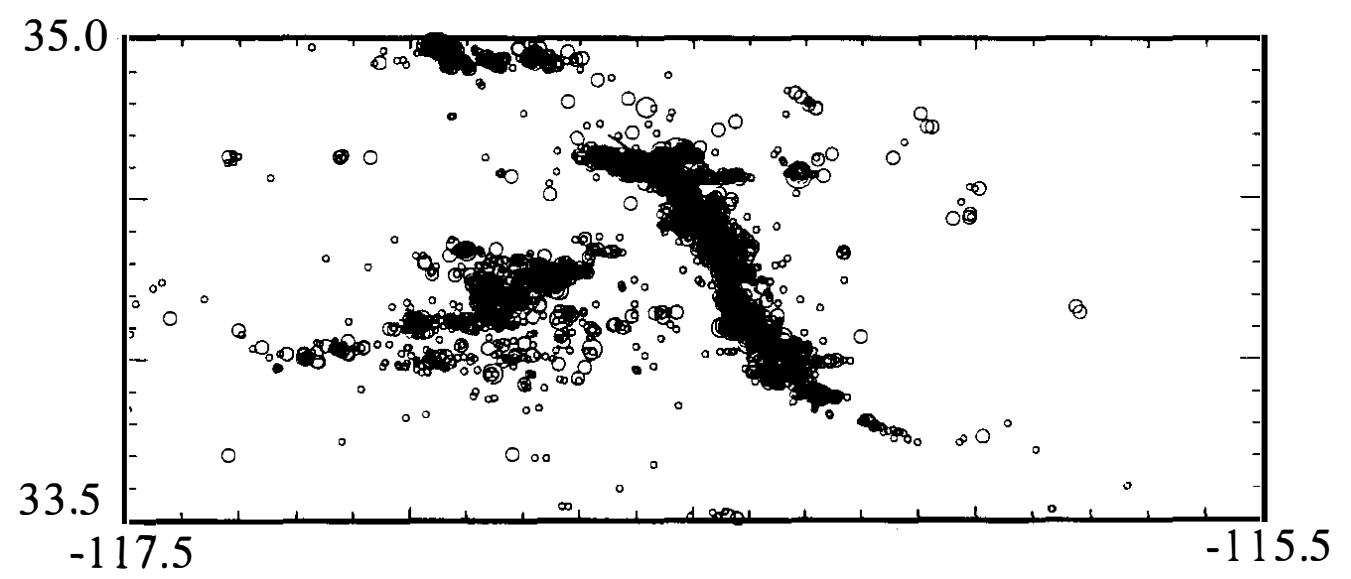

(c)

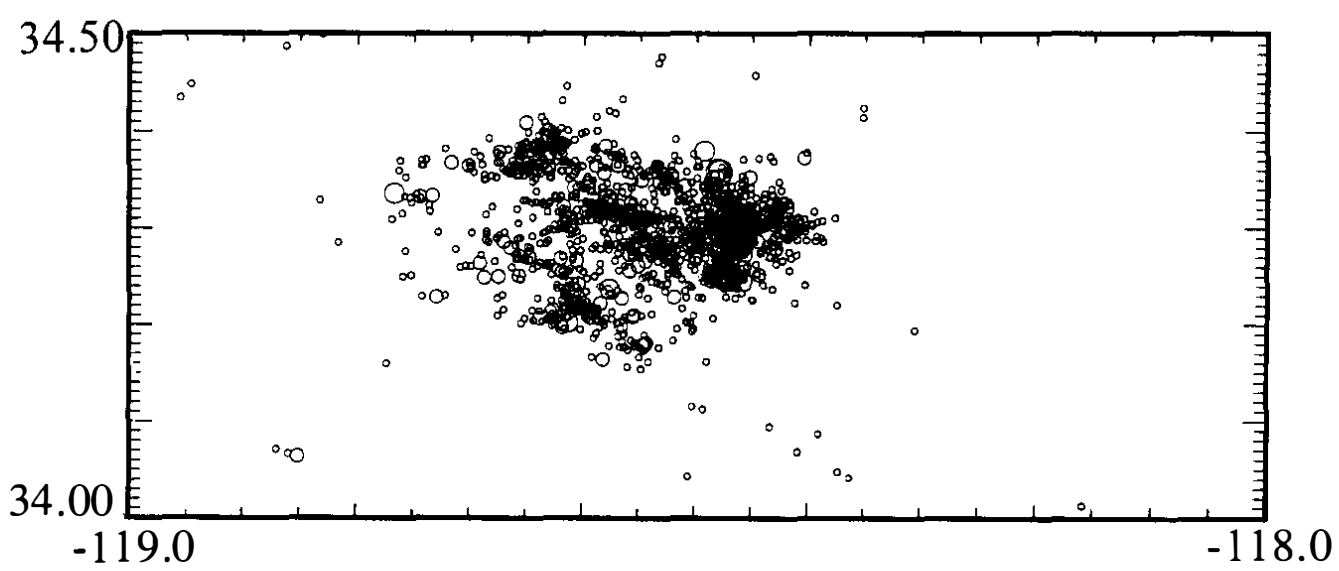


and the Philippine Sea Plate. In the region southeastern of Taiwan, the Philippine Sea Plate moves in the $\mathrm{N} 50^{\circ} \mathrm{W}$ direction, toward the island of Taiwan, at a rate of $7 \pm 4 \mathrm{~cm} / \mathrm{yr}$. (Huchon, 1986; Karig and Cordwell, 1986; Minster and Jorden, 1979; Ranken et al., 1984; Seno, 1977; Seno et al., 1987, 1993). The Philippine Sea Plate subducts north easterly beneath the Eurasian Plate along Ryukyu Trench, then changes its strike from northeast-southwest to nearly east-west as it approaches Taiwan. The collision of the Philippine Sea Plate with Eurasian plate between Hualien and Taitung in the island of Taiwan has resulted a high seismicity in this region as shown in Figure 2. The seismicity of this region has shown a clear subduction zone, and a distinctive collisional margin in the Longitudinal Valley. The mainshock of the May 6, 1986 earthquake, triggered another swarm of seismicity about $20 \mathrm{~km}$ east of the main rupture zone. The location of this seismic swarm is very close to the Meilun Fault. Although there is no surface rupture related to this event, the induced seismicity in the second region is very similar to the so called the compound earthquake. There are two distinct seismic zones in this sequence, thus revealing an association with two different subsurface ruptured planes. It is reasonable to assume that there are two distinct processes acting on each ruptured plane. These processes could be linked or could interact with each other. Therefore, an attempt is made here to model this sequence of earthquakes with a quasi-static model. Under this model, it is only important to assure the existence and scale of the inducing force. How the force acts on each fault plane or the rate of this force is irrelevant to this assumption. There are another two interesting earthquakes which happened on Nov. 1986 and Dec. 1991. The Nov. 14, 1986 ( $M_{s}$ $=6.3)$ event, located at $23.901^{\circ} \mathrm{N}, 121.574^{\circ} \mathrm{E}$, and the Nov. $14,1986\left(M_{s}=6.1\right)$ event at $23.866^{\circ} \mathrm{N}, 121.711^{\circ} \mathrm{E}$ are typical compound earthquakes. The first event of the $1991 \mathrm{com}-$ pound earthquake was on Dec. $14,1991\left(M_{s}=6.5\right)$, at $23.8723^{\circ} \mathrm{N}, 121.547^{\circ} \mathrm{E}$, and the second event was on Dec. $14,1991\left(M_{s}=6.7\right)$, at $23.761^{\circ} \mathrm{N}, 121.628^{\circ} \mathrm{E}$, and they were only about $20 \mathrm{~km}$ apart.

The "compound earthquake" as defined by Scholz (1990, p.210), 'is two or more events, often of a similar size, occur on near by but different rupture surface close together in time, but with a delay such that their rupture times do not overlap.' There are two types of compound earthquakes. Type I: earthquake that ruptures on adjacent parts of the fault with the same mechanism, such as aftershocks, may be a manifestation of time dependence of strength. Type II: the compound earthquake that does not occur on contiguous rupture surface, is less understood, and the change in pore pressure due to the first event bringing the second fault closer to the failure condition is one possible explanation. The Type II compound earthquakes have occurred repeatedly in the South Iceland seismic zone (Einarsson et al., 1981), clearly with several mainshocks in each sequence rupturing on different faults, offset in a direction normal to their strikes. Another typical case of such compound earthquakes occurred in the Imperical Valley, California where it demonstrated a case of triggering between non-parallel faults which can be explained by the change in pore pressure and normal stress due to the first event. Also in the Icelandic case, the compound earthquake sometimes progresses in a single direction, and by that defines the earthquake's migration. The most frequently cited case of earthquake migrating phenomenon was the rupturing on the North Anatolian Fault in a sequence of six large earthquakes that progressed from east to west over the period of 1939-67 

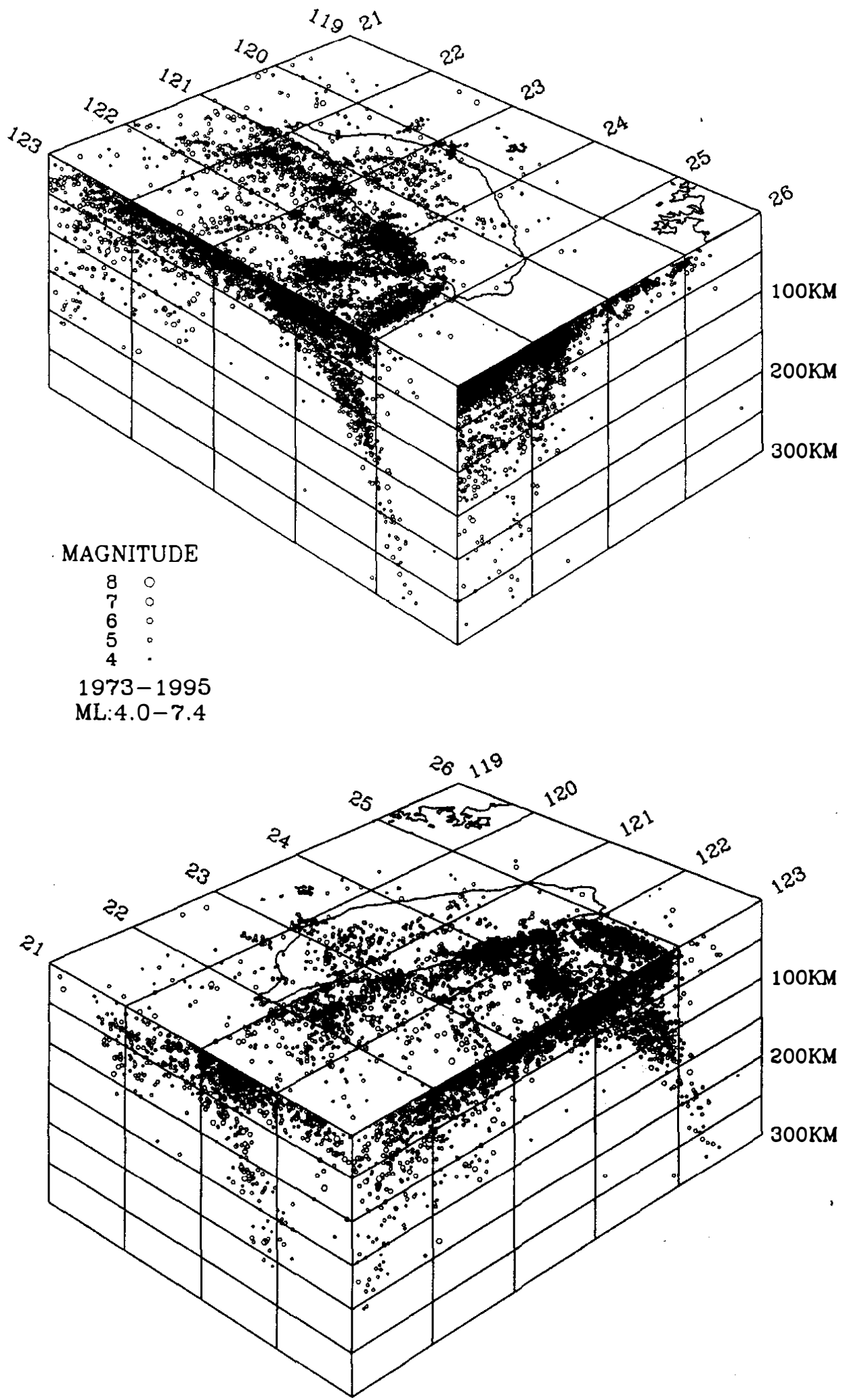

Fig. 2. Seismicity map of Taiwan. Only magnitude $\left(M_{L}\right)$ from 4.0 to 7.4 occurring from 1973 to 1995 are plotted. The subduction zone in eastern Taiwan extending into about a $300 \mathrm{~km}$ depth is shown in this seismicity plot. 
(Allen, 1969).

The Nov. 1986 and Dec. 1991 earthquakes were located in the offshore region of Eastern Taiwan, where the estimated errors in locating earthquakes is $\pm 2.0 \mathrm{~km}$ (Chen and Wang, 1988) due to the poorly defined subsurface velocity layer boundaries there. For this reason, it is difficult to analyze the spatial distribution of aftershocks of these two major events. However, those events did decay very rapidly as in the case of the May 1986 event. The daily number of aftershocks for the May, Nov. 1986 and Dec. 1991 earthquakes are shown in Figure 3. It is noted that even the aftershocks of the Nov. $1986\left(M_{s}=7.8\right)$ event dropped back to a normal level in about 10 days after the mainshock. Both the Nov. 1986 and Dec. 1991 compound earthquakes had secondary events located northwest of the mainshock's epicenter which is consistent with the direction of plate convergence ( $\mathrm{N} 60^{\circ} \mathrm{W}$, Huchon et al., 1986). Besides the 1972 event, the epicenters of magnitude 6 and greater earthquakes in this region migrating south-easterly, that is opposite to the direction of plate convergence as shown in Figure 4 . The migration of earthquakes in the Hualien region of eastern Taiwan provides another example of this phenomenon.

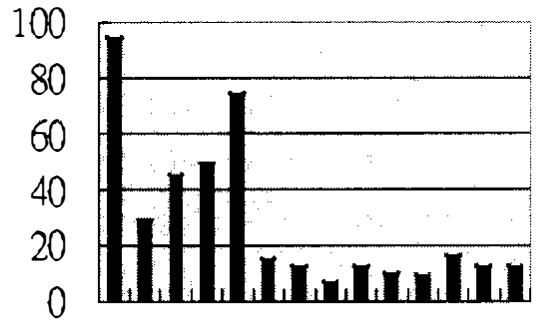

$\begin{array}{lllllll}20 & 22 & 24 & 26 & 28 & 30 & 1\end{array}$
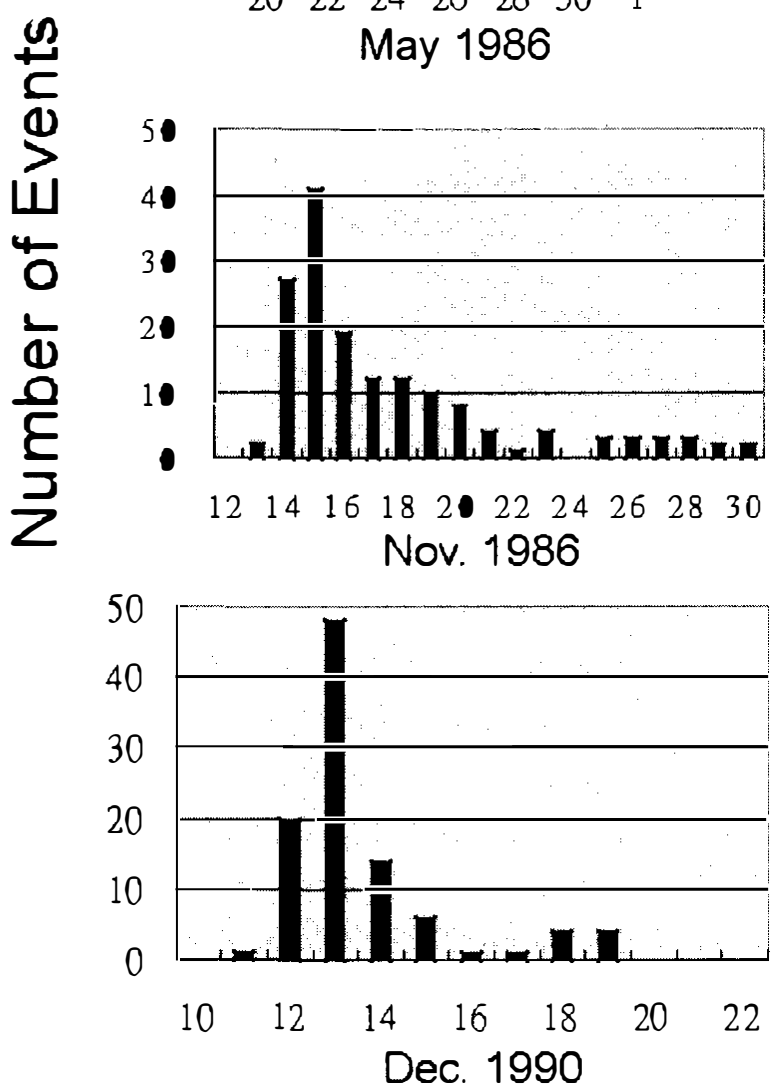

(a)

Fig. 3. Daily aftershocks for three major earthquakes in the studied region. (a) Aftershocks of May 20, 1986 earthquake with $M_{D}>2$. These aftershocks were collected by the temporary seismic network of the Institute of Earth Sciences, Academia Sinica. (b) Aftershocks of Nov. 1986 earthquake with $M_{D}>4$. Events were lo-cated by the Taiwan Teleseismic Network (TTSN). (c) Aftershocks of the Dec. 1991 earthquake with $M_{D}$ $>4$. with events also located by TTSN.

(c) 


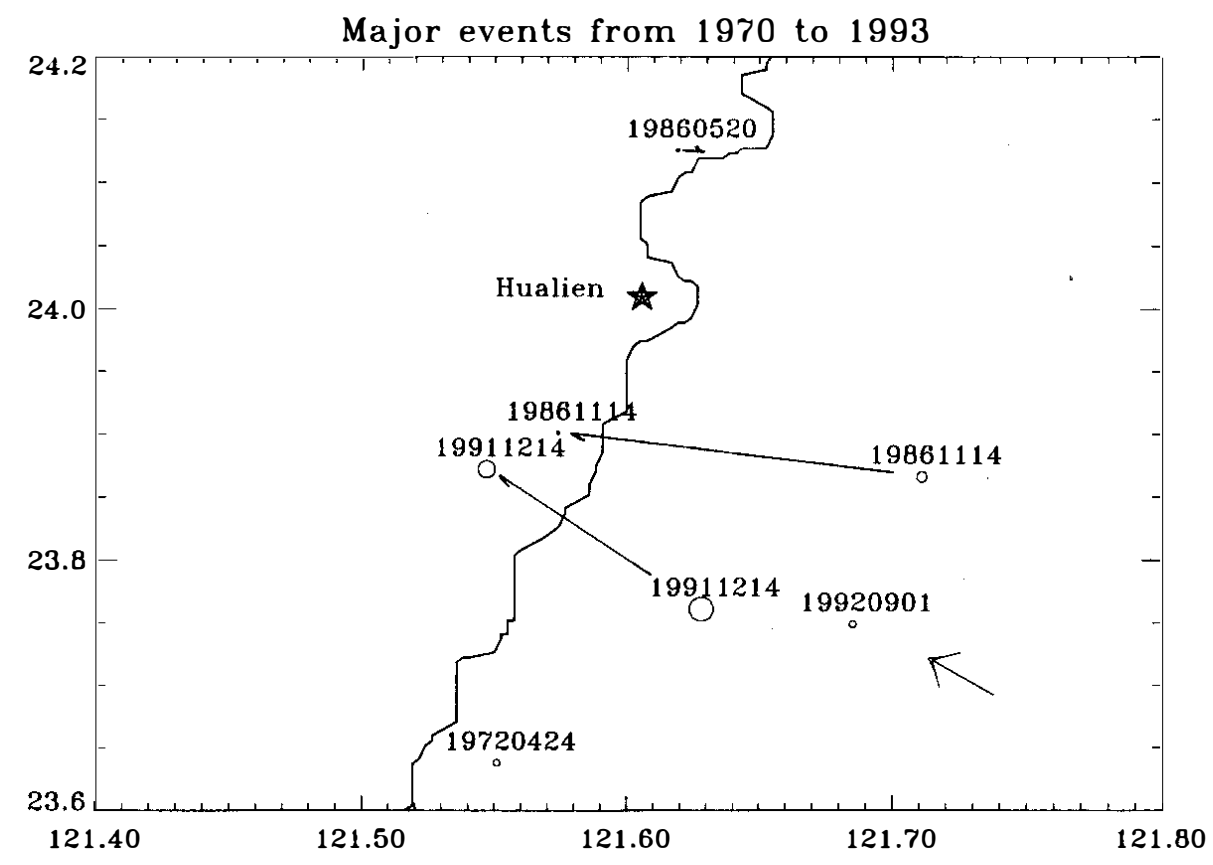

Fig. 4. Magnitude 6 and greater earthquakes located by the TTSN in the Hualien area from 1970 to 1993 . The epicenter of these events migrate southeasterly in the direction opposite to the local principal stress direction except for the 1972 event. The large arrow denotes the direction of plate converge $\left(\mathrm{N} 60^{\circ} \mathrm{W}\right)$. The two small arrows indicate the migrating direction of two compound earthquakes.

The aftershocks of the May 1986 Hualien earthquake in eastern Taiwan showed an eastward migrating pattern, as reported by Chen and Wang (1986), Liaw et al. (1986) and Tsai (1987).The rate of these aftershocks decayed very rapidly within a few tens of day which was different from those of many other major events, where aftershock zone is still very active even years after rupture. The seismicity dropped back to a normal level about 10 days after the May 1986 Hualien mainshock. The aftershocks of this event were monitored by the temporary seismic network of the Institute of Earth Sciences, Academia Sinica and were relocated using

Table 1. The $\mathrm{P}$ wave velocity model used to relocate earthquakes in Hualien area.

\begin{tabular}{cc}
\hline Depth $(\mathrm{km})$ & P wave velocity $(\mathrm{km} / \mathrm{sec})$ \\
\hline $0-5$ & 5.8 \\
$5-10$ & 6.0 \\
$10-15$ & 6.4 \\
$15-25$ & 6.7 \\
$25-35$ & 7.0 \\
$35-$ & 7.8 \\
\hline
\end{tabular}




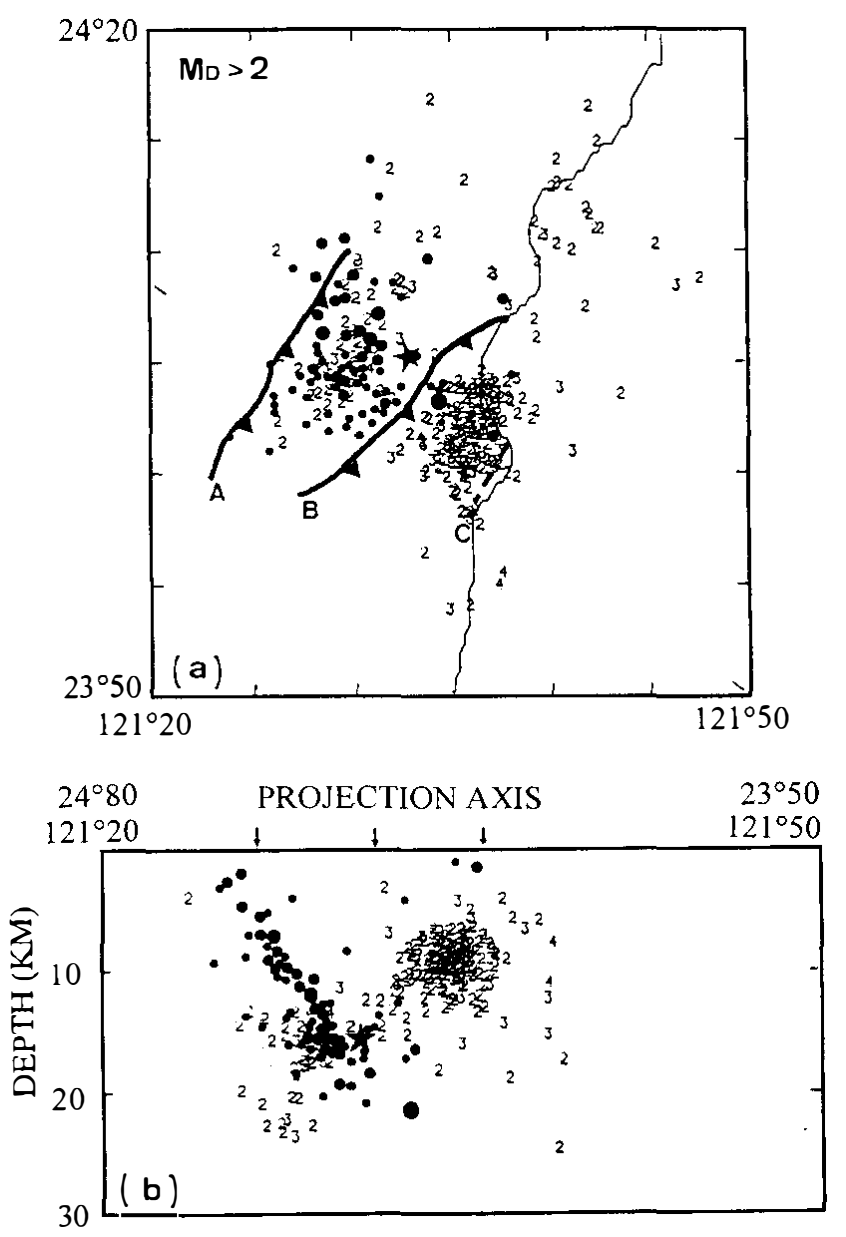

Fig. 5. Relocated aftershocks of the May 20, 1986 Hualien earthquake and major faults in this area. Events shown with dots were located with TTSN, and events relocated with the temperate network are shown in numbers. The magnitude of the events is corresponds to the numbers indicated. (After Tsai, 1987)

a local horizontal-layered velocity model by Tsai (1987) as shown in Table 1. Major faults and relocated events are shown in Figure 5, where aftershocks are clustered into two groups on the surface projection. From this high precision seismicity plot, one can find that aftershocks are clustered on the upper blocks at both thrust faults. Secondly, the east dipping fault plane associated with the mainshock can be clearly defined by hypocenter distribution. The dipping of second faults can not be clearly seen from seismicity and a very concentrated cluster was found instead of a planar distribution. When the daily events were separated for different zones, it can be found that the number of events in the mainshock region, denoted by $\mathrm{S} 1$ in Figure 6, changed from 90 to 10 events/day one day after the mainshock. On the other hand, the region east of the mainshock, S2 in Figure 6, did not have any abnormal seismic activity on May 20 but did gradually increase to about 80 events/day on May 24, and fall back to low seismicity afterward. From the exchange of seismicity on these two zones, it is believed that events in region S2 either were triggered or migrated from the mainshock at S1. To study the temporal distribution of aftershock, the relocated daily seismicity from May 20 to June 2, 
1986, are shown in Figure 7 from which the northeastern migration pattern can be easily found. Another interesting feature of this sequence is the aftershock expansion which took place about 10 days after the mainshock. At this period, the aftershocks did not cluster as a group. On the contrary, they expanded from epicenter of the mainshock to the adjacent regions. The expansion phenomena can be explained throughout the Type II model of Yamashita and Knopoff (1987), as aftershocks were caused by sort of chain reaction on coalescence of nearby small fractures. But, this mechanism cannot explains the migrating pattern seen right after the mainshock. The change in pore pressure due to mainshock might be able to explain the seismicity migrating from zone S1 to S2, but not the expansion pattern happened 10 days after the mainshock.

The postseismic displacement seen on most of the major events has been interpreted by the viscoelastic response of the lower crust and upper mantle by Yu et al. (1996) and many others. It is the intent here to study the observed phenomena and explain such mechanisms of migration throughout the viscoelastic relaxing process of the asthenosphere.

\section{NUMERICAL MODEL}

Stress change resulting from the slip on fault is concentrated at the fault tip (Das and Scholz, 1982). Li et al. (1987) also stated that shear stress is the dominant force in the earthquake triggering mechanism. However, these statements are valid only for the case of strike slip faulting. The coseismic displacement and stress change at surface and underground due to an earthquake faulting in a homogenous half-space can be computed with the formula of Okada

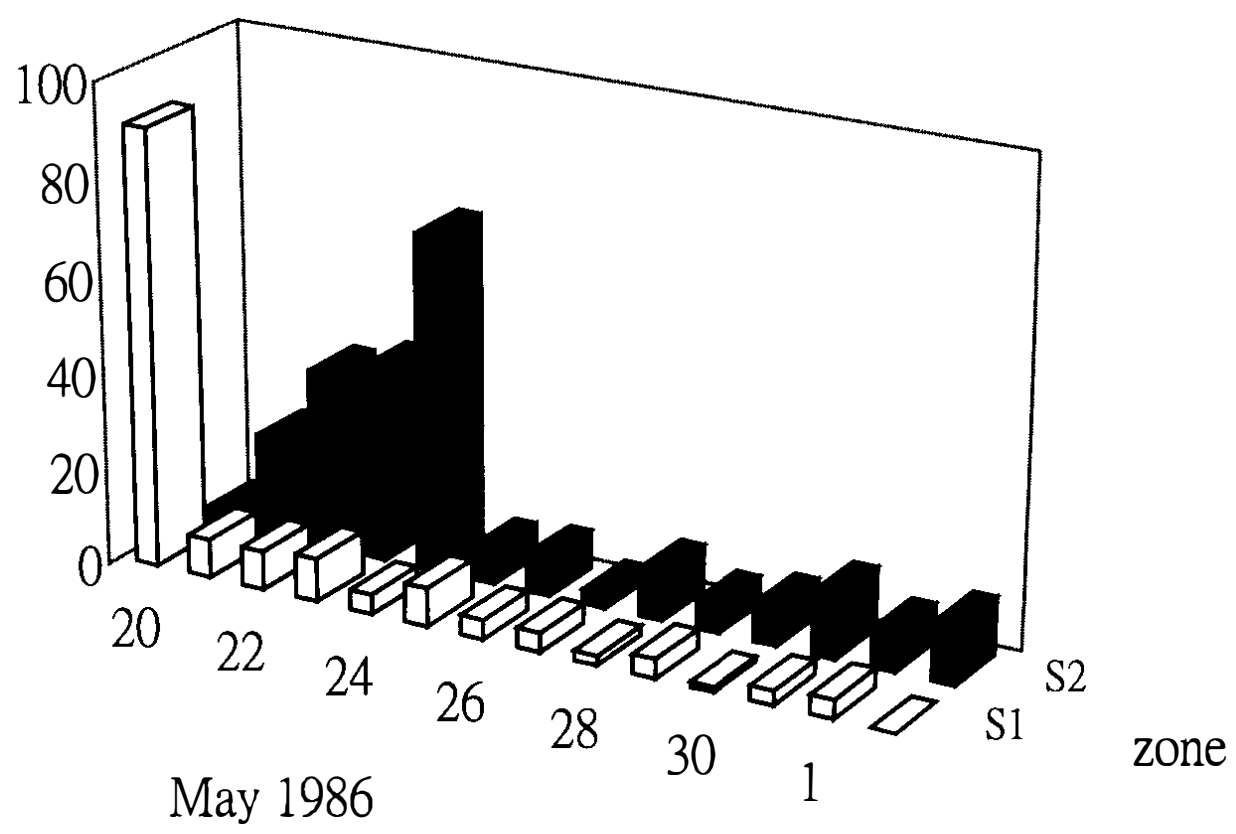

Fig. 6. Daily aftershocks of the May 20, 1986 Hualien earthquake. The S1 zone denotes the ruptured region of the mainshock and S2 represents the area east of the mainshock which was triggered by the mainshock. These events were collected and relocated by the temporary seismic network of the Institute of Earth Sciences, Academia Sinica. 

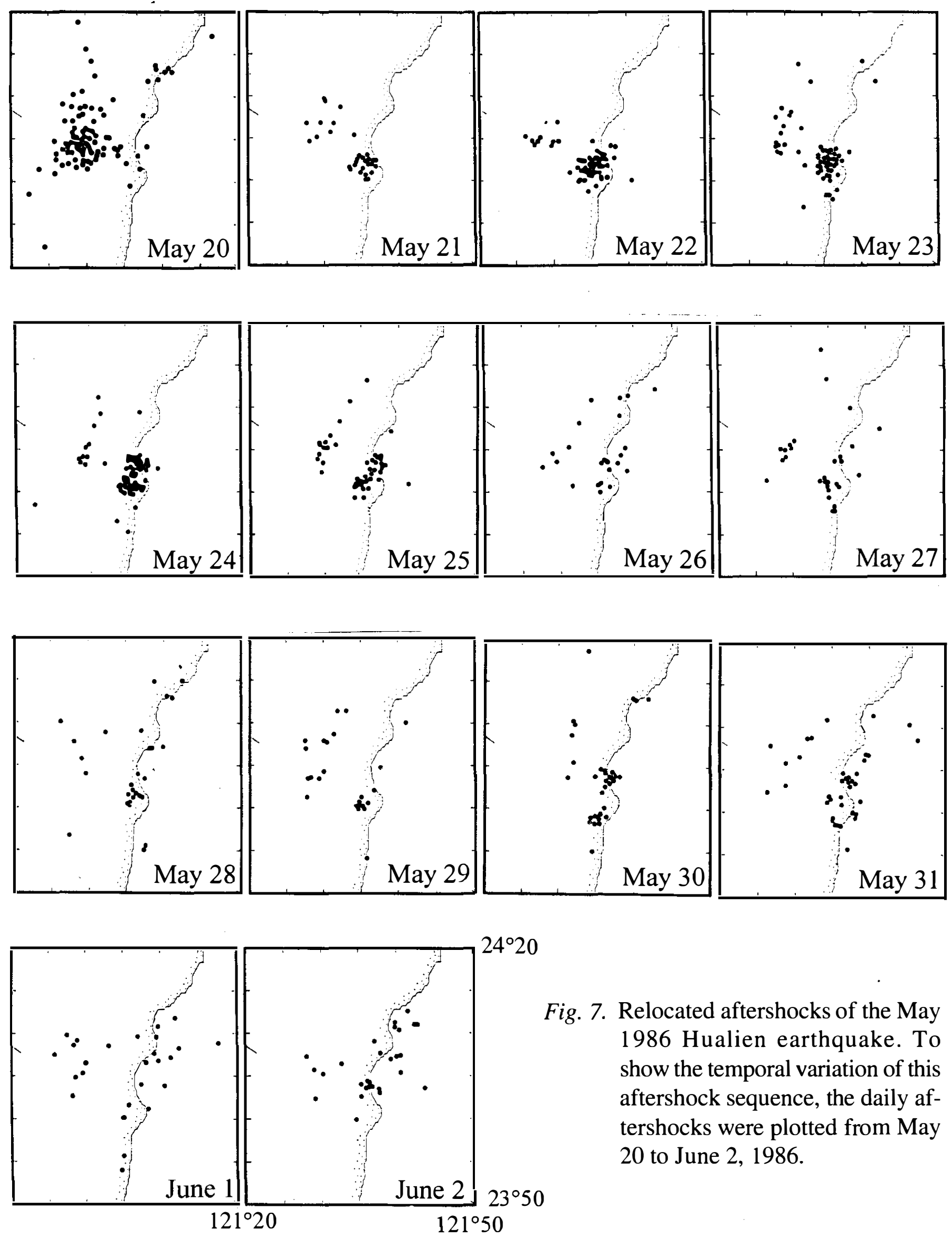

Fig. 7. Relocated aftershocks of the May 1986 Hualien earthquake. To show the temporal variation of this aftershock sequence, the daily aftershocks were plotted from May 20 to June 2, 1986.

$$
121^{\circ} 20 \quad 121^{\circ} 50
$$


$(1982,1995)$. It is found that stress change is concentrated at the edge of the fault, and the shear stress is dominated in the case of strike slip faulting. On the other hand, normal stress controls the case of dip slip faulting (Yu, 1995).

The May 20, 1986 Hualien earthquake, $M_{L}=6.5$, at $24^{\circ} 4.9^{\prime} \mathrm{N}, 121^{\circ} 35.49^{\prime} \mathrm{E}$, with a focal depth $15.8 \mathrm{Km}$ (Tsai et al, 1986) is a thrust faulting with a $20^{\circ} \mathrm{E}$ strike shown from the focal mechanism, which is consistent with the orientation of major faults in this area. To model both the co- and postseismic displacements due to slip on these dip slip faults, the gravitationalviscoelastic displacement model due to a fault in an elastic layer overlying a viscoelastic half space developed by Rundle (1978), Yu (1995), Fernàndez et al. (1996) are used. This involves calculating Green's functions for the point thrust source in an elastic-gravitational layer. The viscoelastic half-space behaves as a Maxwell solid. The gravity is incorporated into this calculation because it contributes a measurable amount to the displacements generated by the thrust faults [Rundle, 1982]. The reduced form of the governing equation that is solved for a viscoelastic gravitational half-space is (Love, 1911; Rundle, 1982):

$$
\nabla^{2} u+\frac{1}{1-2 \sigma} \nabla \nabla \cdot u+\frac{\rho_{0} g}{\mu} \nabla\left(u \cdot e_{z}\right)-\frac{\rho_{0} g}{\mu} e_{z} \nabla \cdot u=0
$$

where $u$ is the perturbed displacement vector in cylindrical coordinates $(r, \theta, z), r$ is distance, $\theta$ is the azimuth, $z$ is depth, $\sigma$ is the Poisson's ratio, $g$ is the gravitational acceleration, $\rho_{0}$ is the density, and $\mu$ is the rigidity. The correspondent principle is used to introduce time dependence (Lee, 1955) which assumes that if the solutions to the elastic problem are known, the corresponding viscoelastic solutions can be found by simply replacing the moduli with complex moduli in the expressions for displacements and stresses and computing the inverse transforms (Golden and Graham, 1988). Therefore, the elastic-gravitational solution is directly related to the Laplace transformed viscoelastic gravitational solution. Finally, Green's function is integrated over the entire source region to obtain near field displacements that vary over time from finite fault planes. The actual relaxation time of the asthenosphere (in unit of tau) is found by comparing the computed displacements with those observed. Once this is determined, the viscosity of the viscoelastic medium can be estimated with $\tau=2 \eta / \mu$, where $\eta$ is the viscosity of the Maxwell solid and $\mu$ is the shear modulus which is roughly $10^{11} \mathrm{dyne} / \mathrm{cm}^{2}$. In summary, the viscoelastic-gravitational model used here shows that when a fault ruptures in an elastic layer, the displacement creates a traction on the elastic-viscoelastic boundary. Such traction at depth is propagated upward through the medium to arrive at the surface displacements.

The input parameters are derived from either geological constraints or seismic data. The parameters of modeling for the fault ruptured by the mainshock are as follows: strike $=\mathrm{N} 20^{\circ} \mathrm{E}$, $\operatorname{dip}=60^{\circ}$, length $=35 \mathrm{~km}$ and depth for an upper edge of the fault $=0 \mathrm{~km}$, which means that this fault ruptures to the surface, and the width of ruptured fault plane $=16 \mathrm{~km}$. For the secondary fault triggered by the mainshock, strike $=\mathrm{N} 55^{\circ} \mathrm{E}$, dip $=60^{\circ}$, length $=30 \mathrm{~km}$, depth $=5$ $\mathrm{km}$, and width of the ruptured fault plane $=8 \mathrm{~km}$. Inverting the seismic moment and coseismic displacement data measured by Yu and Liu (1989), the slip of the fault due to mainshock is estimated at about $30 \mathrm{~cm}$. The thickness of the crust in this region is not well-known; thus, it is 
(a)

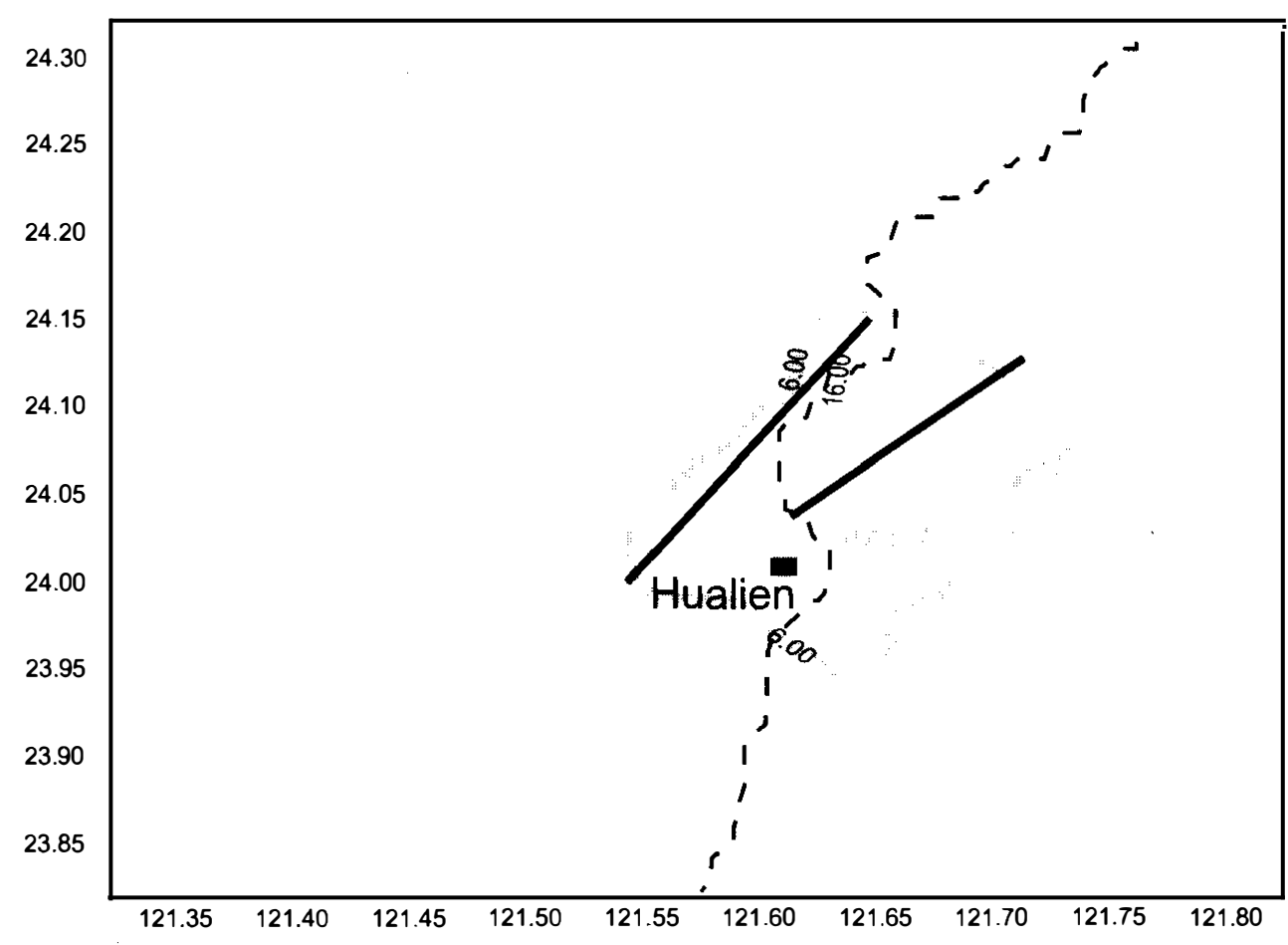

18.00

16.00

14.00

12.00

10.00

8.00

6.00

4.00

2.00

0.00

$-2.00$

$-4.00$

45.00

40.00

35.00

30.00

(b)

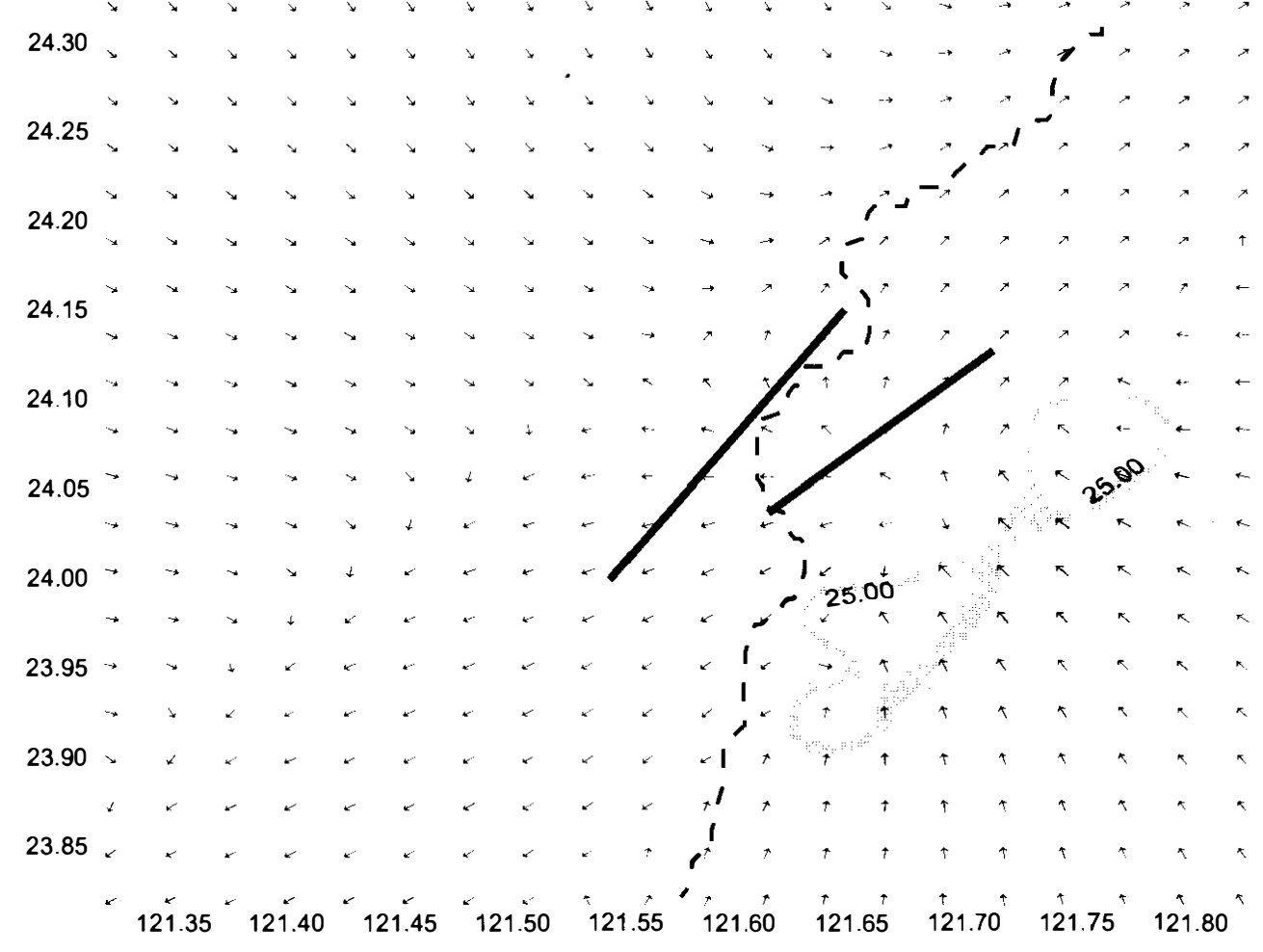

25.00

20.00

15.00

10.00

0.00

Fig. 8. Coseismic displacement field for the May 1986 Hualien earthquake. The two thick lines represent the ruptured faults associated with this event. (a) The contoured vertical displacement field in unit of $\mathrm{cm}$. (b) The contoured horizontal displacement field, with the plotted arrow corresponding to the size and direction of the displacement field at each point. For the detailed modeling parameters, please refer to the text. 


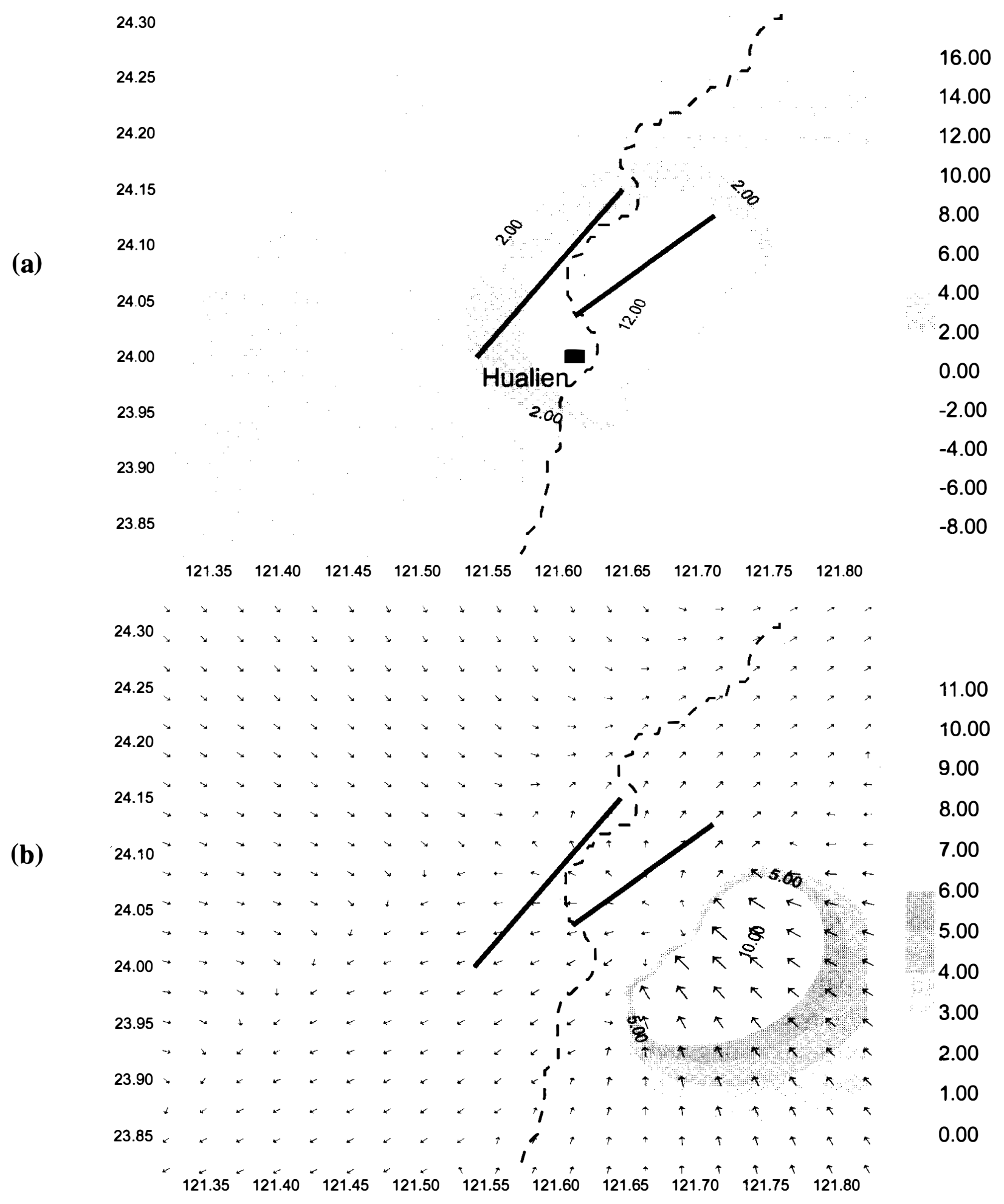

Fig. 9. The same as Figure 8 except for $t=0.5 \tau$, half relaxed stage.

assumed to be equal to $20 \mathrm{~km}$ which means that the mainshock ruptured the entire elastic layer. This assumption only affects the computed magnitude and not the pattern of the associated displacement field (Yu et al., 1996). The computed vertical and horizontal displacement due to the mainshock is shown in Figure 8. The coseismic vertical component displacement 
Vertical displacement at fully relaxed stage

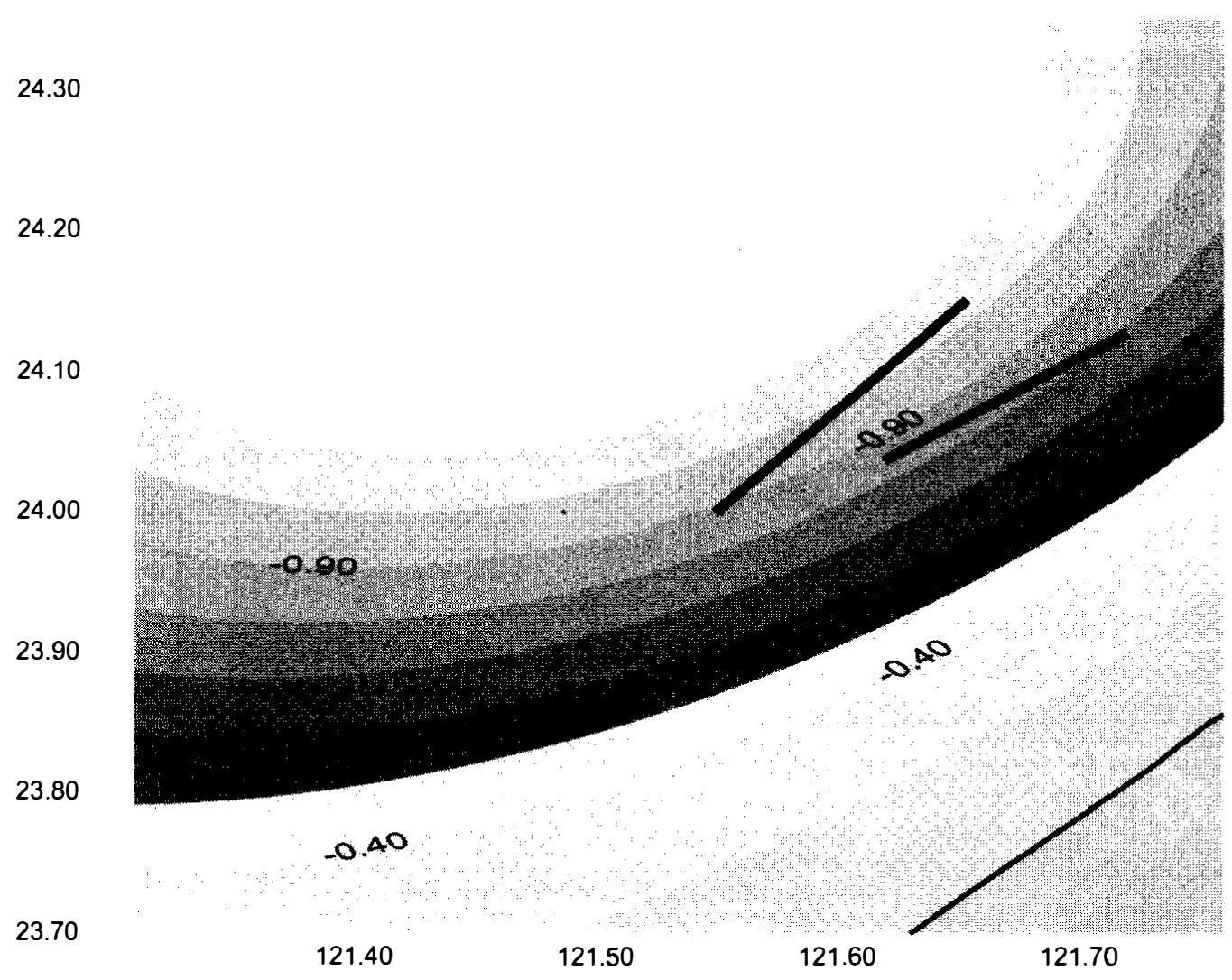

Fig. 10. Vertical postseismic displacement field for the May 1986 Hualien earthquake at $\mathrm{t}=100 \tau$, fully relaxed stage. The two thick lines represent the ruptured faults associate.

(top panel of Fig. 8) has a maximum uplift between the two faults and coincides with the epicenter of the mainshock. Meanwhile, the horizontal component has a maximum displacement about $20 \mathrm{~km}$ away from the fault. Comparing this computed result with the observed seismicity, it is very interesting to notice that those aftershocks occurred in a very short period after the mainshock was located inside the region of maximum vertical displacement. This also agrees with their previous conclusion that normal stress is the dominant force in the case of dip slip faulting. To find out the temporal behavior of aftershocks, the viscoelastic half space is modeled as Maxwell fluid. Because of not knowing the relaxation time of this region, the authors assume the asthenosphere is half relaxed $(t=0.5 \tau)$ in a very short period after the mainshock, due to the rapid decay of seismic activity in this region. Again, the computed postseismic displacement field due to these two faults is shown in Figure 9. Comparing to that shown in Figure 8, the maximum vertical displacement field migrated eastward, while the pattern of horizontal displacement remained almost unchanged. This migrating phenomenon is also found in the aftershocks shortly after the mainshock (c.f. Fig. 7). Furthermore, assuming $\mathrm{t}=100 \tau$ which represents a fully relaxed stage, the displacement field is computed and 
shown in Figure 10. The expansion of the vertical displacement field is consistent with a similar pattern found in the expansion of aftershocks. The peak value of the computed displacement field at the fully relaxed stage is about $1 \%$ of coseismic only, which provides a mean to illustrate the temporal decay of aftershocks that is often seen after major earthquakes, as described by Omri's Law. The sensitivity test with various modeling parameters shows that the strike of fault will affect the direction of migration, and the dip of fault will affect the magnitude and the location of the maximum displacement field. The shear modulus, density of the layer and dislocation on the ruptured fault affects only the computed magnitude but not the pattern.

\section{SUMMARY AND DISCUSSION}

The migration and expansion patterns of aftershocks in the May 1986 Hualien earthquake are unique. Common aftershock activity did not drop back to normal level until several years after the mainshock, but only took tens of day in this case. Most of all, the migrating pattern seen in this Hualien earthquake has not been reported in other places. Several earthquakes with migrating phenomena reported by Einarsson et al. (1981), Allen (1969)and many others, which are, however, representing a sequence of major events in the same or adjacent fault systems. Stress propagation due to tectonic process, change in pore pressure or the viscoelastic effect of the asthenosphere has been interpreted as one of the possible mechanisms for this migrating seismicity. From numerical modeling, it is found that viscoelastic relaxation is the only mechanism which can provide a reasonable explanation for both the expansion and migrating of the aftershocks seen in this event. Also by matching the aftershock seismicity and computed models, it can be concluded that the relaxation time of the asthenosphere in the Hualien region is very short, only tens of day. This phenomenon might be similar to the case of the Landers earthquake, in which the relaxation time in the region was only 34 days (Shen $e t$ al, 1995; Yu et al., 1996). The possible reasons for a short relaxation time are either because of an existing inter-crustal layer that is rich in quartz or water (Turrcotte et al, 1984) or because of the special property of the lower crust and upper mantle in the Hualien region. This low relaxation time of the asthenosphere may also explain the observations of short reoccurrence time (20-30 years) of magnitude 7 and larger earthquakes in this region. The crustal property in this region may be very special that it can accumulate and release stress in shorter period of time. The relaxation time for the asthenosphere in southwest Japan is about 20 years (Savage, 1995). Thus, the reoccurrence time of similar magnitude earthquakes is in the order of 100200 years (Thatcher and Rundle, 1984).

Besides this aftershock expansion of the May 1986 earthquake, there are two pairs of compound earthquakes showing southeasterly drifting in this region. The drifting direction of these compound earthquakes is consistent to the direction of plate convergence in East Taiwan. This evidence reinforces the idea that most compound earthquakes do migrate, and the principal mechanism of such migrating comes from local tectonic force. Another possible mechanism for earthquake migrating is the traction at boundary of asthenosphere and lithosphere or the influence of long wavelength elastic wave propagating along the boundary of crust and mantle as proposed by Aki (1979). Thus, the stress redistribution after a major event 
plus the tectonic force might be adequate to account for the phenomenon of earthquake migrating.

Acknowledgments We like to express our gratitude to Dr. Y. T. Yeh for his kindly support and thoughtful guidance. Thanks should also go to Dr. J. H. Wang, his comment and suggestion have improved the quality of this work. Two anonymous reviews gave precious comments and corrected our English writing that help us to improve this manuscript . T. T. Yu is supported by the postdoctoral research fellowship of Institute of Earth Sciences, Academia Sinica, and this project is funded by National Science Council of Republic of China under contract NSC86-211-M001-009.

\section{REFERENCES}

Aki, K., 1979: Characterization of barriers on an earthquake faults. J. Geophys. Res., 84, 6140-6148.

Allen, C. R., 1969: Active faulting in northern Turkey. Contr. No. 1577, Div. Geol. Sci. Cail. Inst; Tech., 32pp.

Chen, K. C. and J. H. Wang, 1988: A study on aftershocks and focal mechanisms of two 1986 earthquakes in Hualien, Taiwan. Proc. Geol. Soc. China, 31, 65-72.

Das, S. and C. Scholz, 1982: Off fault aftershock clusters caused by shear stress increase. Bull. Seism. Soc. Am., 71, 1669-1675.

Dieterich, J. H., 1972: Time dependent friction as a possible mechanism for aftershocks. J. Geophys. Res., 77, 3771-3781.

Einarsson, P., S. Bjornsson, G. Foulger, R. Stefansson and T. Skafadottir, 1981: Seismicity pattern in the south Iceland seismic zone. In: D. Simpson and P. Richards (Eds.), Earthquake prediction, an international review, M. Ewing Ser. 4, Washington, D.C.,AGU, 141-152.

Fernàndez J., T. T. Yu and J. B. Rundle, 1996: Horizontal viscoelastic-gravitational displacement due to a rectangular dipping thrust fault in a layered Earth model. J. Geophys. Res., 101, 13,581-13,594.

Golden, J. M. and G. A. C. Graham, 1988: Boundary value problems in linear viscoelasticity, Springer-Verlag, New York, 266pp.

Huchon, P., 1986: Comment on "Kinematics of the Philippine Sea Plate by B. Ranken, R. K. Cardwell, and D. E. Karig". Tectonics, 5, 165-168.

Karig, D. E. and R. K. Cardwell, 1986: Reply to "Comment on 'Kinematics of the Philippine Sea Plate' by B. Ranken, R. K. Cardwell and D. E. Karig". Tectonics, 5, 169-170.

Kostrov, B. V. and S. D., 1988: Principles of earthquake source mechanics. Cambridge University Press, 286pp.

Lee, E. H., 1955: Stress analysis in viscoelastic bodies. J. Appl. Mech., 13, 183-190.

Li, V. C., S. H. Seal and T. Cao, 1987: Postseismic stress and pore pressure readjustment and aftershock distributions. Tectonophysics, 144, 37-54.

Liaw, Z. S, C. S. Wang and Y. T. Yeh, 1986: A study of aftershocks of the 20 May 1986 
Hualien earthquake. Bull. Inst. Earth Sci, Academia Sinica, 16, 15-28.

Love, A. E. H., 1911: Some problems in geodynamics. Cambridge University Press, New York, $180 \mathrm{pp}$.

Minster, J. B. and T. H. Jordan, 1979: Rotation vectors for the Philippine and Rivera plates (abstract). EOS trans. AGU, 60, p.958.

Nur, A. and J. R. Book, 1972: Aftershocks caused by pore fluid flow. Science, 175, 885-887.

Okada, Y., 1985: Surface deformation due to shear and tensile faults in a half-space. Bull. Seism. Soc. Am., 75, 1135-1154.

Okada, Y., 1992: Internal deformation due to shear and tensile faults in a half-space. Bull. Seism. Soc. Am., 82, 1018-1040.

Omori, F., 1894: On the aftershocks of earthquakes. J. Coll. Sci. Imp. Univ. Tokyo, 7, 111200.

Ranken, B., R. K. Cardwell and D. E. Karig, 1984: Kinematics of the Philippine sea plate. Tectonics, 3, 555-575.

Reuschlè, T., 1990: Slow crack growth and aftershock sequences. Geophys. Res. Lett., 17, 1525-1528.

Rundle, J. B., 1978: Viscoelastic crustal deformation of a layered half-space by point couple source. J. Geophys. Res., 83, 5937-5945.

Rundle, J. B., 1982: Viscoelastic-gravitational deformation by a rectangular thrust fault in a layered Earth. J. Geophys. Res., 87, 10,729-10,744.

Savage, J. C., 1995: Interseismic uplift at the Nankai subduction zone, southwest Japan, 19511990. J. Geophys. Res., 100, 6339-6350.

Scholz, C. H., 1968: Microfracture, aftershocks and seismicity. Bull. Seism. Soc. Am., 58, 1117-1130.

Scholz, C. H., 1990: The mechanics of earthquakes and faulting. Cambridge University Press, 439pp.

Seno, T., 1977: The instantaneous rotation vector of the Philippine Sea plate relative to the Eurasian plate. Tectonophysics, 42, 209-229.

Seno, T., S. Stein and A. F. Gripp, 1993: A model for the motion of the Philippine Sea plate consistent with NUVEL-1 and geological data. J. Geophys. Res., 98, 17,941-17,948.

Shen, Z. K., D. D. Jackson, Y. Feng, M. Cline, M. Kim, P. Fang and Y. Bock, 1994: Postseismic deformation following the Landers earthquake, California, 28 June 1992. Bull. Seism. Soc. Am., 84, 780-791.

Thatcher, W. and J. B. Rundle, 1984: A viscoelastic coupling model for the cyclic deformation due to periodically repeated earthquakes at subduction zones. J. Geophys. Res., 87, 7631-7640.

Tsai, S. F., 1987: The May 1986 Hualien earthquake sequence and its relation with the regional tectonic stress. Master thesis, National Taiwan University, 132pp.

Tsai, C. C., Y. T. Yeh, K. L. Wen, S. N. Chen and M. H. Kao, 1986: The Hualien earthquake of May 20, 1986: strong ground motion data and response spectra. Bull. Inst. Earth Sci., Academia Sinica, 16, 29-64.

Turcotte, D. L., J. Y, Liu and F. H. Kulhawy, 1984: The role of an intracrustal asthenosphere 
on the behavior of major strike-slip faults. J. Geophys. Res., 89, 5801-5816.

Yamastita, T. and L. Knopoff, 1987: Models of aftershock occurrence. Geophys. J. R. Astr. Soc., 91, 13-26.

Yu, S. B. and C. C. Liu, 1986: Coseismic deformation associated with the May 1986 Hualien earthquake. Bull. Inst. Earth Sci., Academia Sinica, 16, 73-84.

Yu, T. T., 1995: Crustal deformation due to a dipping fault in an elastic gravitational layer overlying a viscoelastic gravitational half space: models and applications. $\mathrm{Ph}$. D. Dissertation, University of Colorado at Boulder, USA, 174pp.

Yu, T. T., J .B. Rundle and J. Fernàndez, 1996: Surface deformation due to a strike-slip fault in an elastic gravitational layer overlying a viscoelastic gravitational half-space. $J$. Geophys. Res., 101, 3199-3214. 